UNIVERSITY OF ILLINOIS

LIBRARY

class ${ }_{1910}$ Book 65 volume 



\section{AN ANALYSIS OF THE NORMAL CHANGES OF REGENERATION RATE IN LIMNODRILUS CLAPAREDEIANUS (SMITH)}

FRANK L. PINCKNEY

\section{THESIS FOR THE DEGREE OF BACHELOR OF ARTS}

\section{GFNERAL SCIFNCE}

IN THE

COLLEGE OF SCIENCE

OF THE

\section{UNIVERSITY OF ILLINOIS}

Presented June, 1910 w 


$$
\begin{aligned}
& 1910 \\
& F 65
\end{aligned}
$$


UNIVERSITY OF ILLINOIS

May $30-1900$

THIS IS TO CERTIFY THAT THE THESIS PREPARED UNDER MY SUPERVISION BY Frank L. Pinckney ENTITLD Un analysis of the nom al changes of regeneration rate in Limnodrilus blaparedeianus

IS APPROVED BY ME AS FULFILLING THIS PART OF THE REQUIREMENTS FOR THE

DEGREE OF Bachelor of Crts

in cine recuse

charles Geleny

Instructor in Charge.

Approves: Chur y is tran

HEAD OF DEPARTMENT OF Loo logy-

$1680: 39$ 

AN ANALYSIS OF THE NORMAL CHANGES OF REGTIERATION RATE IN LIMNODRILUS CLAPAREDEIANUS (SMITH).

OBJECT .

The objects in view were;

1.The determination of the manner in which the rate of regeneration changes during ordinary replacement of the removed part.

2.The analysis of the factors controlling this change in rate.

The character of the rate change was determined with considerable accuracy. It was not possible, however, to make more than a slight contribution to the analysis of the factors controlling this change.

\section{METHOD.}

Limnodrilus claparedeianus was the form used in all of the experiments. The technique employed in all cases was practically the same and worms of equal size were used throughout. The worms were found in abundance in a nearby pond and made a very satisfactory form to work upon. They were easily obtained, withstood the laboratory conditions, overcame the shock of the operation in a short time, and the regenerated part could be easily distinguished from the old part because of its comparative lack of pigment. The only objection to Limnodrilus was its great activity, making measurements difficult and necessitating the use of a special method as described later.

Six series of experiments were performed, five with the body cut in two at its midale and one with all of the posterior portion 
Digitized by the Internet Archive in 2013

http://archive.org/details/analysisofnormal00pinc 
of the body removed except the anterior twenty segments. The worms were placed on a flat block of paraffin under a dissecting microscope, and cut at the proper place with a thin, sharp scalpel, the cut being made at right angles to the long axis of the body. The worms were kept in Syracuse watch glasses holding about fifteen cubic centimeters of water, and a new supply of water was given to them each day. The measurements of the regenerating tail were taken three times a week and the temperature recorded every day. During Experiment I food was given the worms twice, but in the other series food was administered once. The food consisted of rich mud, thoroughly heated, so that all organisms contained in it were killed.

The apparatus used in measuring the rorms consisted of an ocular micrometer and a slide, upon which wereplaced two very small glass tubes, the same length as the slide and about one-quarter of an inch apart. The worm was placed in the channel between these two glass tubes which had been filled with water, and as it lengthened out, the tubes were moved closer together, and when the worm had completely straightened itself, a small glass plug was placed in front of, and behind it between the glass tubes, and a large cover glass placed over the entire slide. This held the worm in a straight position and the measurements could be made with considerable accuracy .

\section{DATA.}

The data for each experiment are given in a table, and the rates are represented graphically in the form of curves. Experiment I was performed with the object in view of determining the manner in which the rate changed during the regeneration of the removed part. Eleven norms were operated upon November 29 th and the measurements were made three times a week until February 12th. There 

There are four distinct periods in the development of the new part, as can be seen in the fifth horizontal row of figures in Table 1. During the first period, regeneration is very slow, an average of only .3 millimeters having been replaced in two days. The second period, or period of maximum increase, extended from the fourth to the eighth day and replacement took place at the rate of 1.1 millimeters per day. The third period lasted from the eighth to the thirteenth day and was one of rapld decrease, averaging only .2 millimeters per day. The fourth and last period was one of gradual decrease, averaging .17 millimeters per day and extended over a period of twenty-eight days.

On the twelfth day after the operation, there was a rise in the curve and also a corresponding rise in the temperature. On the fifteenth day there was a drop in the curve and also a drop in the temperature. This shows that the temperature influences the rate of regeneration and should be kept as constant as possible.

The special object in view in Experiment II was the determination of the influence of the amount removed upon the rate of regeneration at the different periods. In this experiment the posterior nine-tenths of the body was removed, while in all of the others, the body was cut in two at its middle. As is shown in row five of Table II, the rate of regeneration in the first period is much slower than it is in Experiment I, and the maximum rate in the second period was reached at a later date. otherwise the curve was not affected.

Experiments III \& IV were performed as checks for the first one, to determine whether the maximum rate occurred at a definite time. In series III the maximum rate was reached on the seventh 

day and in series IV it occurred on the sixth day.

In Experiment $V$ measurements were taken every day with the object of determining more accurately the exact form of the curve of regeneration, special attention being paid to the first period.

Experiment VI was performed for the purpose of securing material for a histological study of the regenerating tissue, with the object of making a comparison of the time of cell differentiation with the rate curve. On account of the unavoidable delay in the experiment, only a slight contribution to this part can be presented.

Owing to the fact that the worms were constantly growing during the experiments and that some possible error might have crept in the measurements, as they were extremely active most of the time, it was rather difficult to get the exact change in the rate of regeneration, but by using a sufficiently large number of worms, and by removing those that were abnormal in any way, the latter error was lessened and the true curve of rate change obtained more accurately.

In all of the data secured, there are four periods of rate change that can be distinctly recognized; (I) an interval of low rate, succeeded by (2) one of rapidly increasing rate, then by (3) one of rapidly decreasing rate and finally (1) an interval in which the rate gradually approaches zero. 

EXPERIMENT I.

Table I.

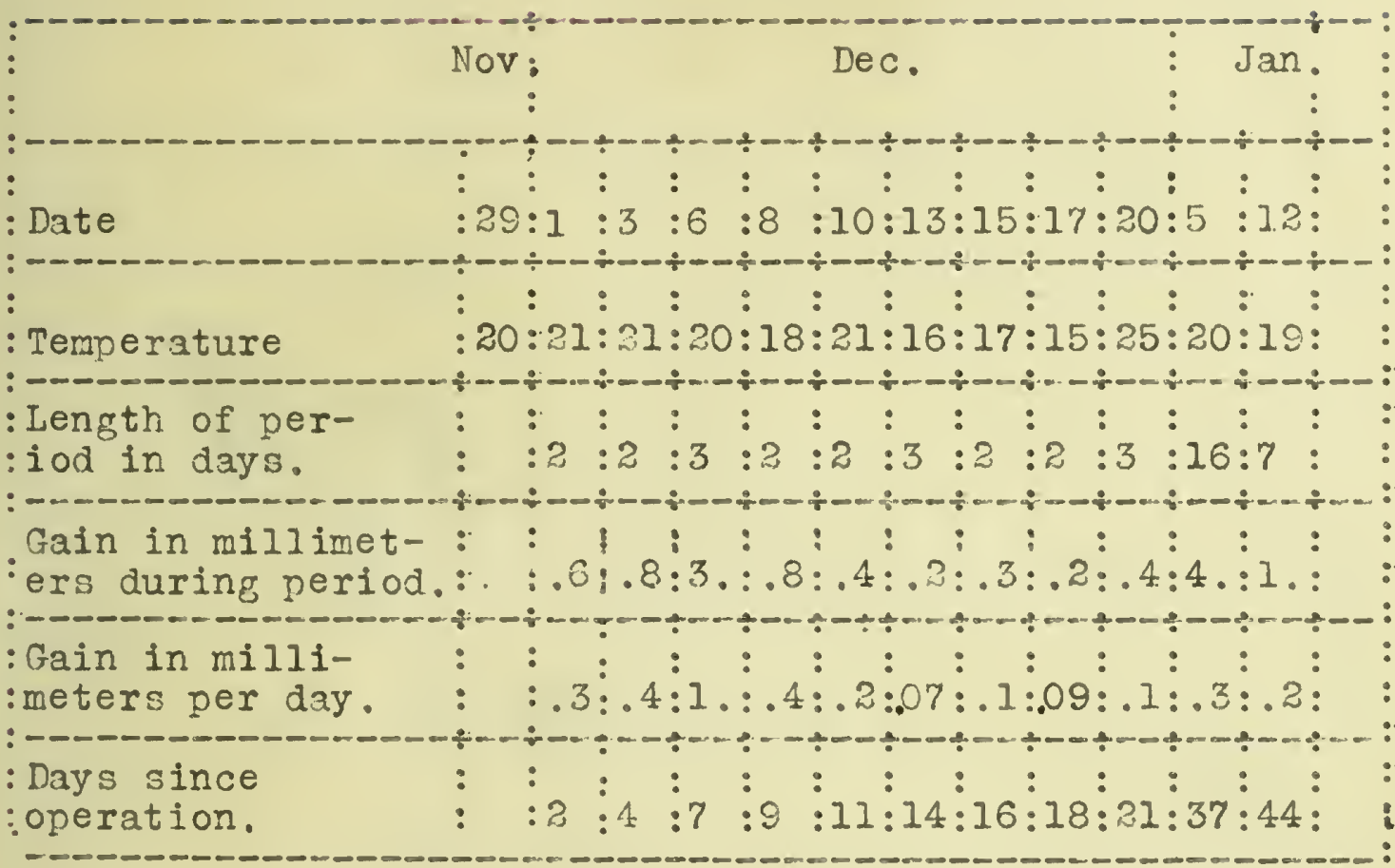

Explanation of Table I.

The first horizontal row of figures gives the dates upon which the measurements were made. The second row shows the average temperature of the days upon which the measurements were taken; this being a very important factor in the rate of regeneration as its variation causes a corresponding variation in the rate. The third row of figures gives the length of the interval between measurements. The fourth row gives the gain in length in millimeters for the period between the measurements. The figures in row five give the gain per day in millimeters, and row six gives the number of days that have elapsed since the operation.

The curves in all of the figures were obtained by using the 



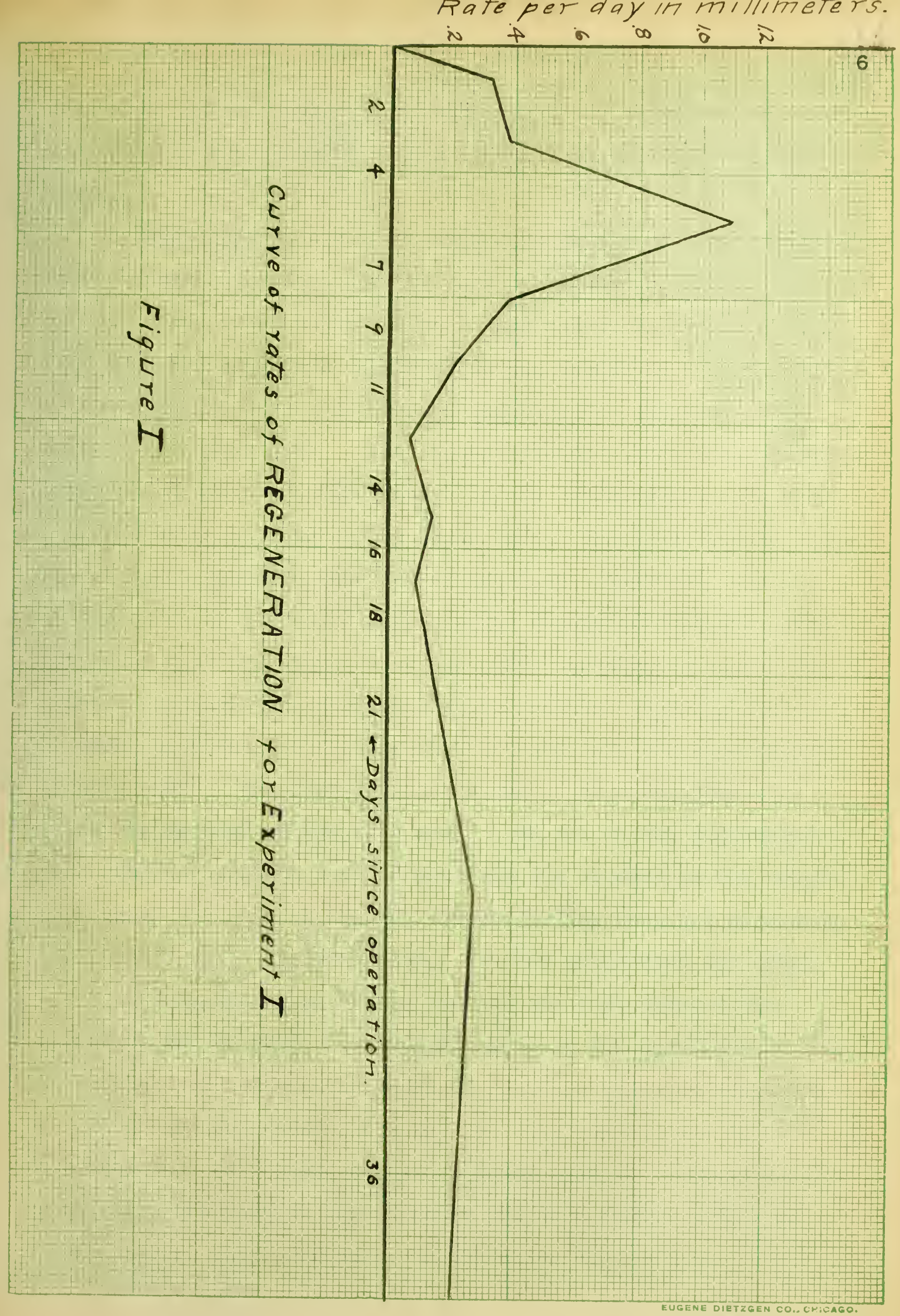



abscissae as the intervals of time since the operation, and the ordinates as the rates of length regenerated per day in millimeters.

In Experiment I, the first period, or period of slow increase, extended over four days and the rate was somewhat faster than it was in the other experiments. This was probably due to the fact that the embryonic cap of cells was formed at a much faster rate and division took place more rapidly, thus increasing the newly regenerated part. The second period, or period of rapid increase, extended from the fourth to the sixth day, the maximum increase being reached on the sixth day. The third period was one of rapid decrease from the sixth to the thirteenth day and at the close of the third period, a new supply of food was given the worms with the result that the curve immediately rose. The temperature also rose at this time, so that the rise was caused no doubt, by these two factors that entered into the experiment at this time. The last period was one of slow decrease and gradually approached the zero mark. In all of the experiments performed, the maximum rate of increase was reached in the neighborhood of the seventh day, the variation from this not exceeding a day and a half on either side. On the thirteenth day after the operation, the curve almost reached the zero mark; on the fifteenth day it rose and dropped again on the seventeenth. By consulting the temperature chart, it is found that the temperature is low on the thirteenth, high on the fifteenth and low on the seventecnth. This shows without a doubt, that the temperature influences the rate of regeneration and is a factor worthy of consideration when performing regeneration experiments. 



\section{EXPERIMENT II.}

Table II

\begin{tabular}{|c|c|}
\hline & December \\
\hline Dat & $6-8: 10: 13: 15: 17: 20: 5: 12:$ \\
\hline rature & 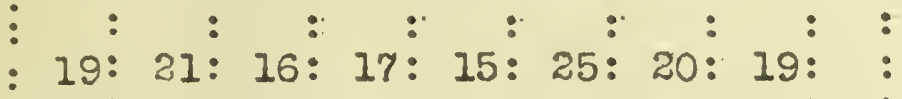 \\
\hline $\begin{array}{l}\text { ength of per- } \\
\text { lod in days. }\end{array}$ & $: 2: 2: 3: 2 \vdots 2: 3: 16: 7:$ \\
\hline $\begin{array}{l}\text { ain in mil } \\
\text { rs during }\end{array}$ & 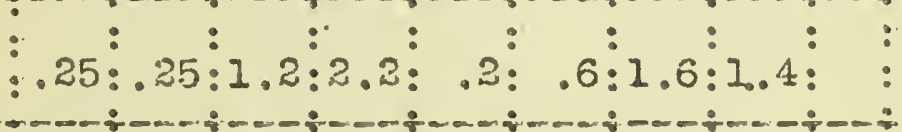 \\
\hline $\begin{array}{l}\text { rain in mi: } \\
\text { ters per }\end{array}$ & 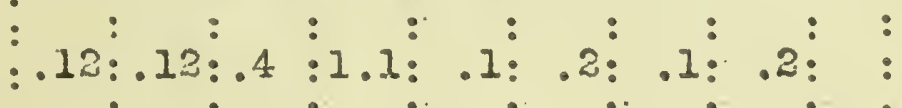 \\
\hline ys $s$ & $: 2: 4: 7: 9: 11: 14: 30: 37:$ \\
\hline
\end{tabular}

For explanation of Table II, see Table I.

Figure II gives the form of the curve plotted from Experiment II. The maximum rate in the second period was reached on the eighth day. Between the tenth and thirteenth day after the operation, the temperature rose from 13 degrees to 25 degrees, which caused the rising of the curve at the beginning of the fourth period. Since there were only five worms left alive at the close of this experiment, the irregularity of the fourth period is probably due to individual variation.

\section{EXPERIMENTS III \& IV.}

In Experiments III \& $\mathrm{IV}$, which were performed as checks to the others, the maximum rate of increase was reached on the 



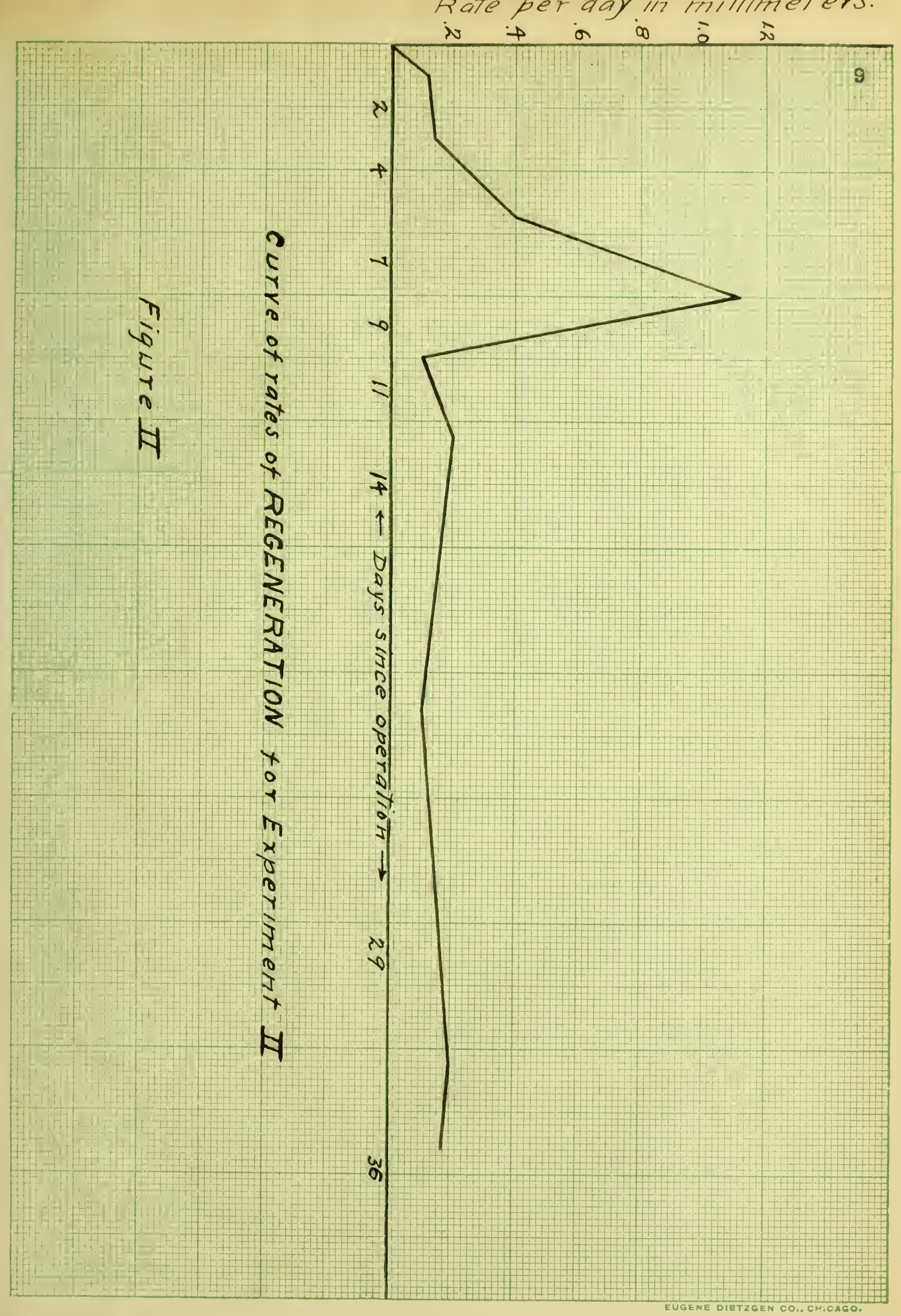



sixth day in Experiment III, and on the seventh day in Experiment IV.

Table III.

\begin{tabular}{|c|c|}
\hline & Tan \\
\hline & January. \\
\hline ate & $: 12-14: 17: 18: 19: 21: 24:$ \\
\hline emperature & $: 18: 21: 18: 18: 14: 18:$ \\
\hline $\begin{array}{l}\text { Length of per- } \\
\text { iod in days. }\end{array}$ & $2 \vdots 3 \vdots 1: 1 \vdots 2 \vdots 3:$ \\
\hline $\begin{array}{l}\text { ain in } \mathrm{mi} \\
\text { rs during }\end{array}$ & $: .14: .03: .26: .07: .08: .12:$ \\
\hline $\begin{array}{l}\text { lain in milli- } \\
\text { eters per day. }\end{array}$ & $\vdots .07: .01: .26 \vdots .07 \vdots: .04 \vdots: .04:$ \\
\hline $5=$ & $2: 5: 6: 7: 9: 12:$ \\
\hline
\end{tabular}

For explanation of Table IIr, see Table I.

Table IV.

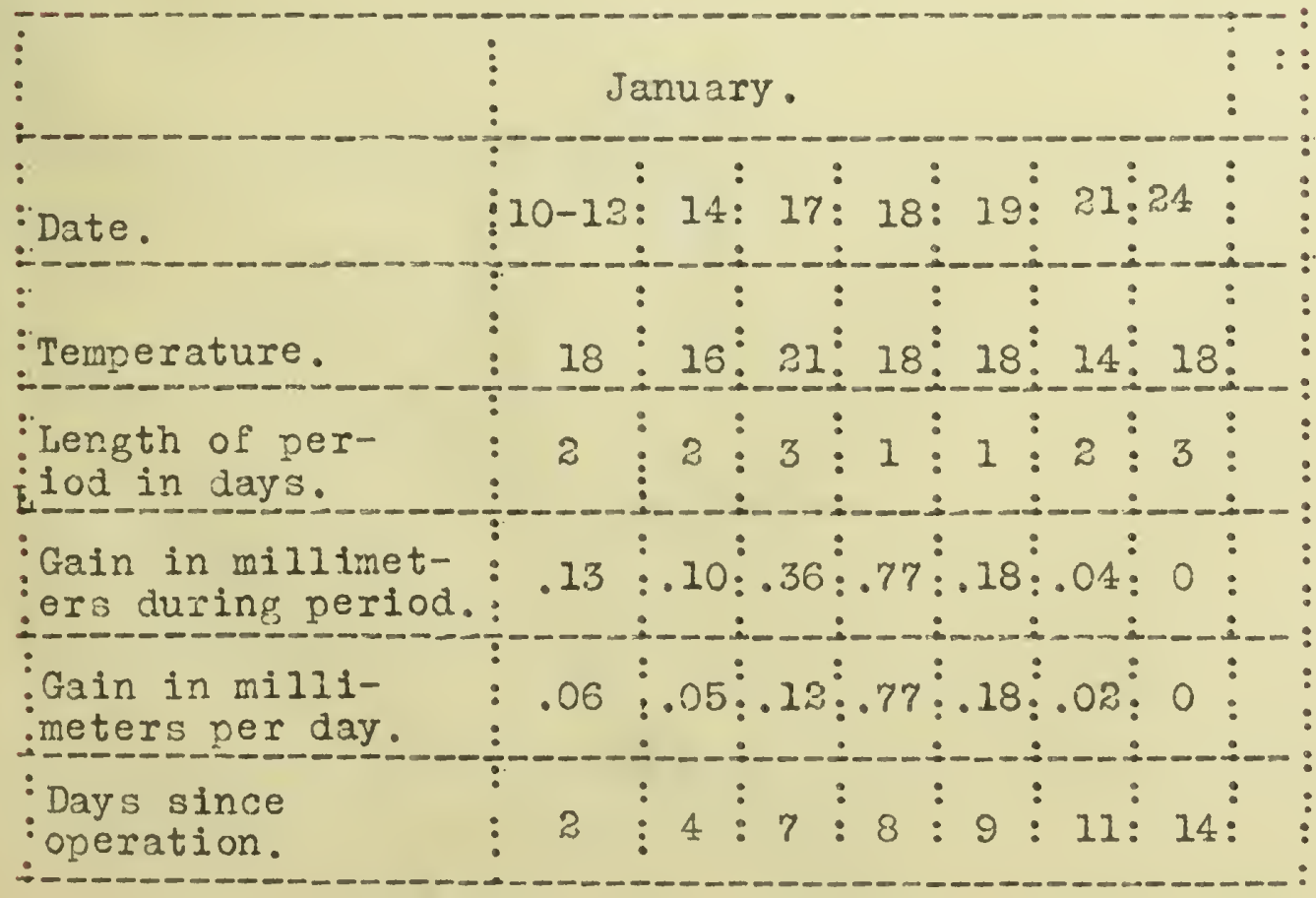





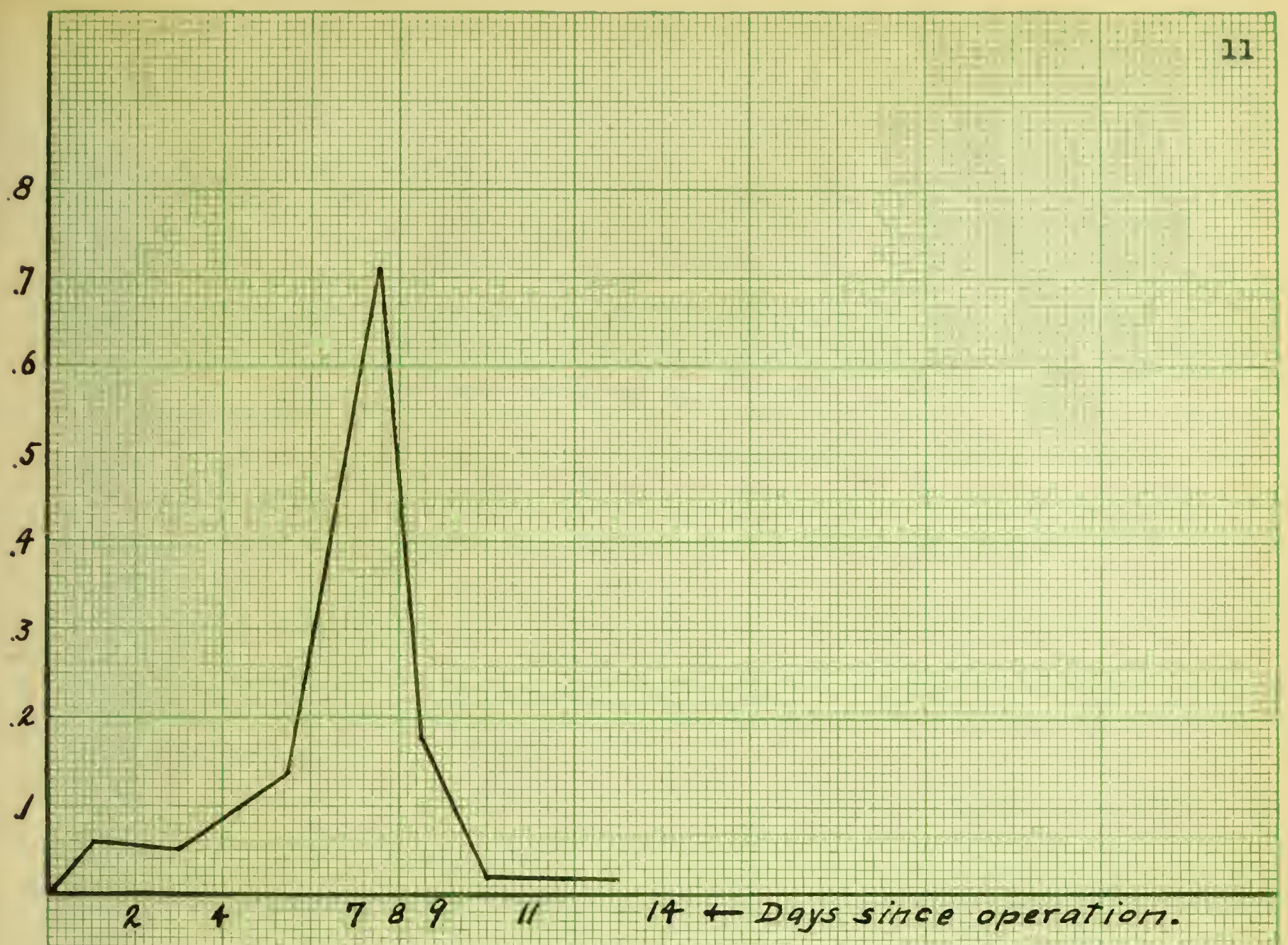

Curve of rates of REGENERATION for Experiment III

Figure III 
iis

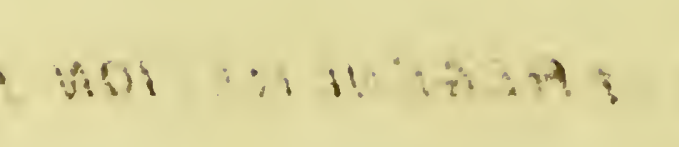




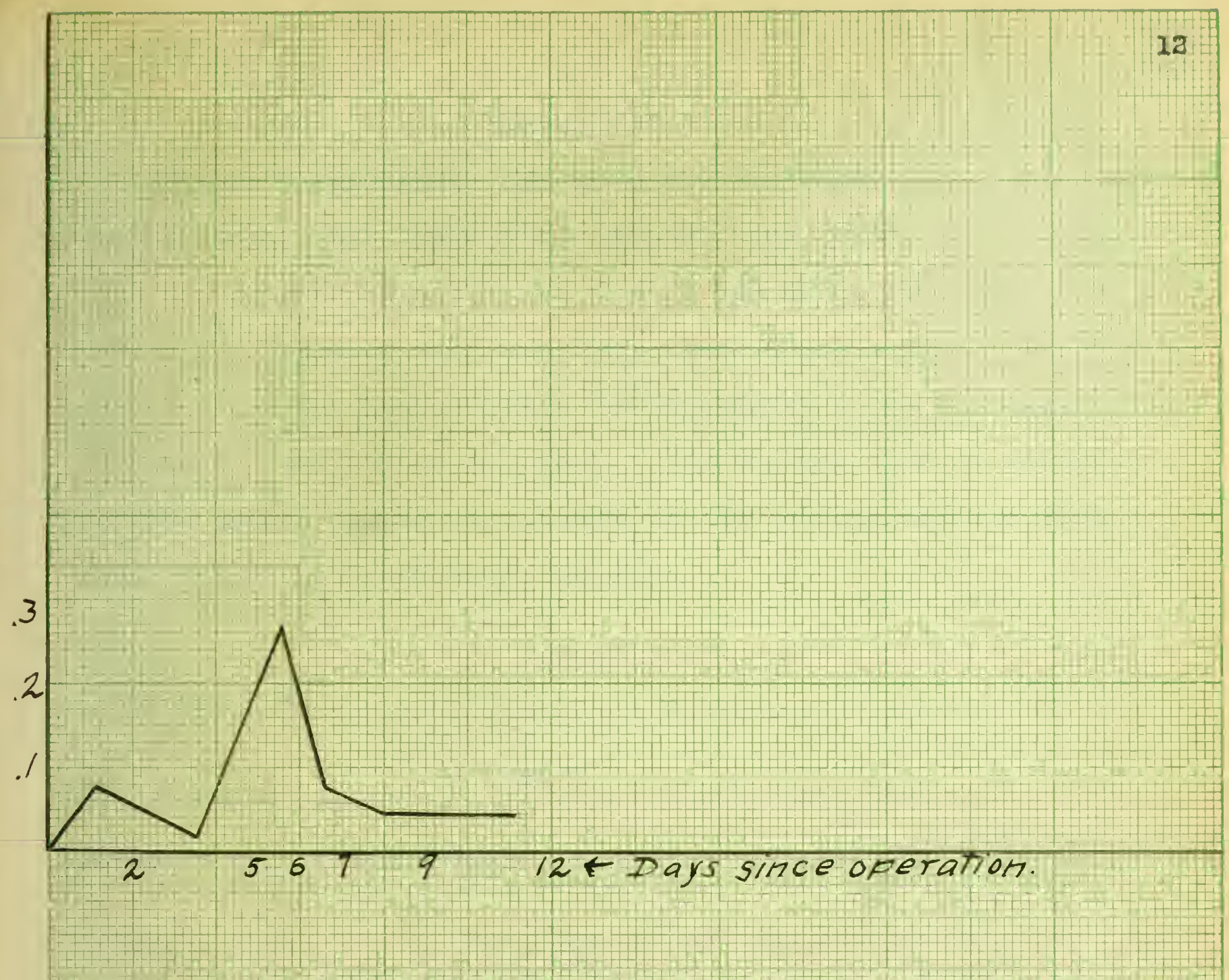

CWTVE of TATES Of REGENERATION for ExpeTImEnT IV

Figure II 



\section{EXPERIMENT V.}

Figure $V$ represents the curve for Experiment $V$ and as these measurements were taken every day, the true course of the curve can be followed more closely than in the other experiments, where measurements were made only three times a week. Table Va gives the daily measurements for Experiment $V$ and the exact increase in rate can be followed. The maximum rate of increase of the second period vas reached on the seventh day, and from this point the curve drops rapidy.

Table V.

\begin{tabular}{|c|c|}
\hline & March. \\
\hline te & 13-14: 15: $16 \vdots 17 \vdots 18 \vdots 19 \vdots 21:$ \\
\hline ratur & $\div 12: 10: 16: 22: 21: 21: 23: 2$ \\
\hline $\begin{array}{l}\text { longth of per- } \\
\text { lod in days. }\end{array}$ & $\vdots 1 \vdots 1 \vdots 1 \vdots 1 \vdots 1 \vdots 1 \vdots 2 \vdots 1$ \\
\hline $\bar{d}$. & $\vdots .16 \vdots 17 \vdots 18 \vdots$ \\
\hline $\begin{array}{l}\text { in } \\
\text { cs pe }\end{array}$ & 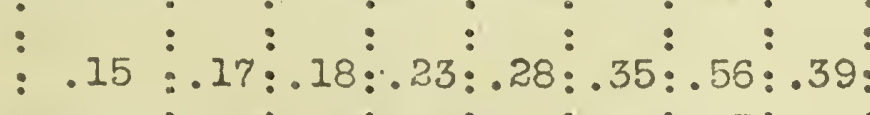 \\
\hline ร5 & $1: 2: 3: 4: 5: 6: 8: 9$ \\
\hline
\end{tabular}

For explanation of Table V, see Table I. 

.6

.5

.4

2

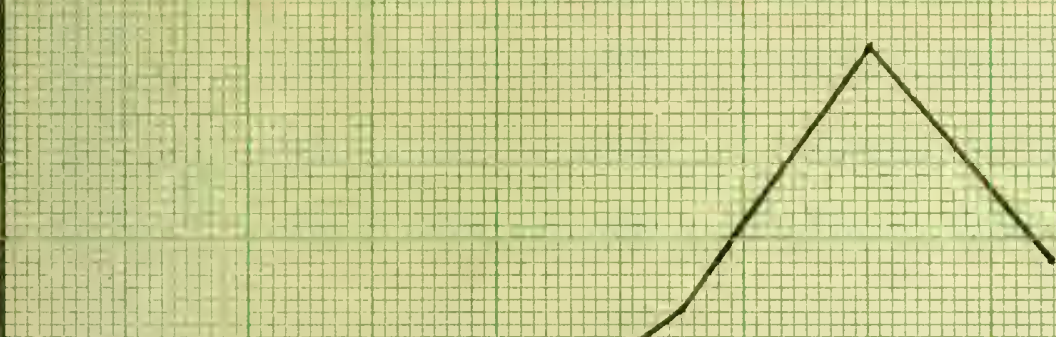

.1

Curve of rates of REGENERATION for Experiment II

Figure I 

Table Va

: Worm: Length: Length: Length: Length: Length: Length: Length: Length: :no. :Mar.14:Mar.15:Mar.16:Mar.17:Mar.13:Mar.19:Mar.21:Mar.22:

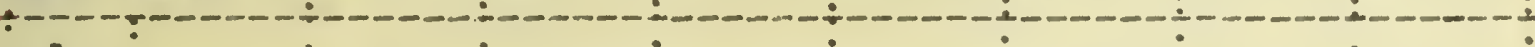

$: 1$ $19 \underline{0} \div-3 \underline{5}$ -38 $\vdots-63$

$: 2$ 15ㄴ. $\div-21$ $.6 \underline{3}$

3 $-13: \div 25 \div-246$ :... $\geq 0$

$4 \vdots 18: 29: 246$

5

$$
\text { 21: }
$$$$
38:-1.55
$$$$
\text { .70 }
$$$$
-1.09 \div-1.38
$$$$
2.94
$$
3.48

$: 6$ : $.27: 46 \quad:-63$

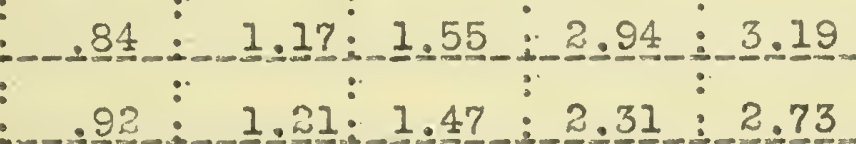$$
: 7
$$

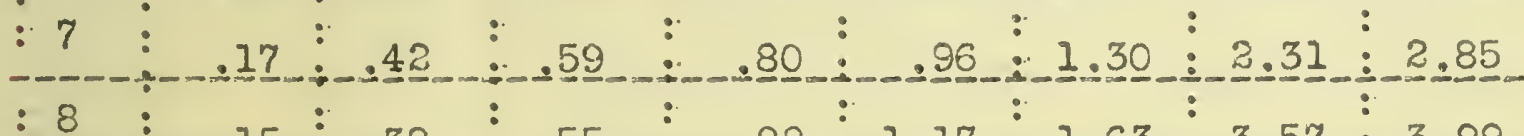
$\because \quad: \quad 0030$ $\div-15: 38 \div-55 \div-88 \div 1.17 \div 1.63 \div 3.57 \div 3.99$

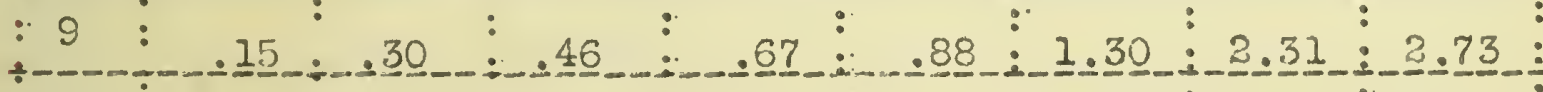

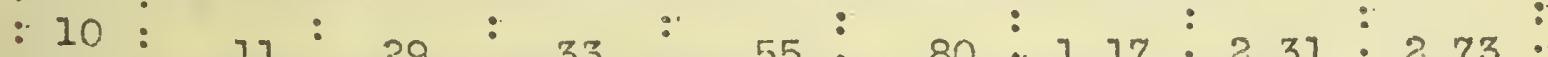

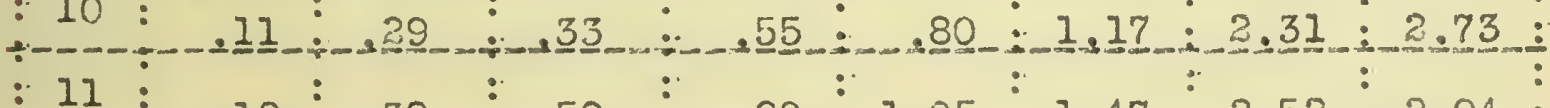

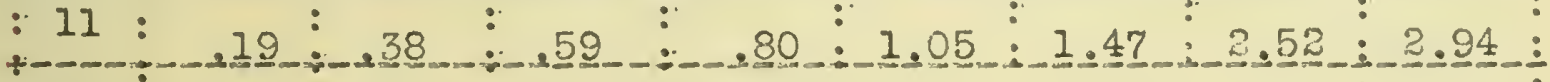

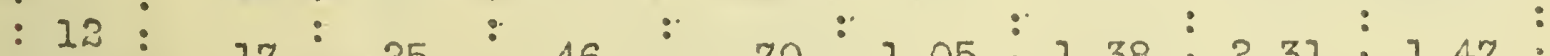
$\div 12 \div 17 \div 25 \div 26 \div-10 \div 1.05 \div 1.38 \div 2.31-1.1 .47-\div$

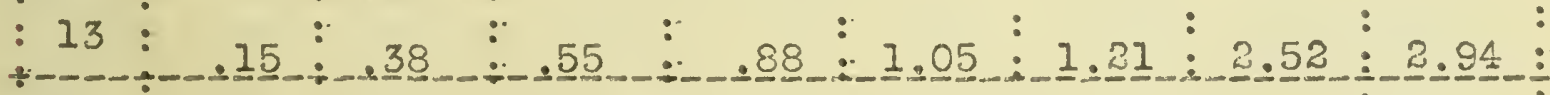

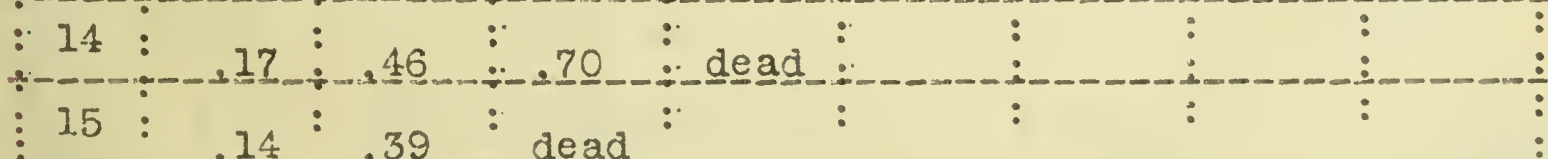

Explanation of Table Va.

The first row of vertical figures gives the number of the worm. The second row of vertical figures gives the total amount regenerated the first day, the third row the amount regenerated in two days, the fourth row the amount regenerated in three days and so on, until the ninth row is reached, which gives the total amount regenerated during the interval of nine days. The millimeter was the unit of measurement used in this experiment. 

EXPERIMENT VI.

From a glance at the different curves, four periods of growth can be recognized, which vary considerably as to their length. The variation is brought about by external factors that affect the animal and also by the behavior of the cells during regeneration. Experiment VI was performed for the purpose of securing material for a histological study of the regenerating tissue with the object of making a comparison of the time of cell differentiation with the rate curve. On account of unavoidable delay in the experiment, only a slight contribution to this can be presented. It was however, possible to make out definitely the fact that the period of maximum rate of regeneration coincides with the beginning of differentiation of the muscle cells. This agrees with Miss Durbin's results in Rana clamatans?

\section{DISGUSSION .}

By comaring the curves of the rate of regeneration with the curves of ordinary growth of an animal, as worked out by Minot,we can readily see the similarity between the two. Minot conducted an elaborate series of experiments upon the rate of growth in rabbits, guinea-pigs and man, and expresses his results graphically by constructing curves showing the percent of increment per day throughout the life of the animal. The curves,

\section{1}

Durbin, Marion 109. Analysis of the Rate of Regeneration throughout the Regenerative Process. Jour.Exp.Zool. Vol.VII. 2 Minot, C,S. '08. Age, Growth and Death. 

when based upon the rate changes, either from the time the egg is fertilized or from the time the animal is born, show that the rate of growth undergoes four different kinds of changes, which correspond in general with the four intervals of change in the rate of regeneration. Minot recognizes two factors controlling the rate of growth; (1) the tendency of undifferentiated cells to multiply; (3) the tendency of undifferentiated cells to differentiate into cells that do not multioly. Since the change in the rate of regeneration and the rate of ordinary growth is similar, it is highly probable that the factors controlling these processes are similar.

There are two possible explanations for the low rate in the first period of regeneration: (1) the shock given the animals by the operation may make them too weak to begin regeneration at once; ( 3 some time is spent in the formation of an embryonic can which serves 35 a basis for the regeneration which is to follow. The nature of the shock of the operation includes such local effects as; (1) the bruising of the flesh on the line of operation and irritation by the water and micro-organlsms in the water; (2) loss of blood and nervous shock due to the pain inflicted by cutting the nerve cord; (3) the loss of energy due to the worm trying to swim or crawl with only a portion of its body. The first day of regeneration of the first period was much faster than the remainin; two or three, and this is accounted for by the purely mechanical rounding off of the cut end. The rapid increase in the second period is explained by the fact that the cells at this time are undifferentiated and are dividing ranidly. After the maximum rate is reached, the cells begin to be 

differentiated and this is probably the cause of the rapld decrease found in the third period and the gradual decrease found in the fourth period.

\section{SUMMARY .}

1. In Limnodrilus claparedeianus the removal of a portion of the posterior part of the body is followed by the regeneration of the part removed.

2. The rate at which this regeneration takes place is not the same for all periods.

3. The operation is followed by an interval of low rate, then by one of rapidly increasing rate, succeeded by one of rapidy decreasing rate and finally a period where the rate is gradually decreasing and approaching zero.

4. The low rate in the regenerating prooess is caused by the combination of two factors; (1) the shock of the injury, (2) the formation of an embryonic cap which serves as a basis for the regeneration that is to follow.

5. The second period, or period of rapid increase, is caused by the rapid division of the undifferentiated cells.

6. In the third and fourth periods differentiation is taking place and the cells are dividing less rapidly.

7. The curves representing the changes in the regeneration rate are similar to the curves of ordinary growth in animals. 8. Since the curves of regeneration rate and ordinary growth rate are similar, we are lead to believe that the factors controlling these two rates are similar. 

TEMPERATURE CHART .

Centegrade.

\begin{tabular}{|c|c|c|c|}
\hline Date & : Average : & : Date & $\begin{array}{l}\text { : Average } \\
\text { :Temperature. }\end{array}$ \\
\hline$-29-09$ & 20 & $1-7-10$ & 21 \\
\hline $1-30-09$ & 25 & $1-8-10$ & 24 \\
\hline $2-1-00$ & 21 & $1-10-10$ & 18 \\
\hline $2-2-09$ & 21 & $1-11-10$ & 18 \\
\hline $2-3-09$ & 21 & $1-12-10$ & 19 \\
\hline $2-5-09$ & 19 & $1-13-10$ & 18 \\
\hline $2-6-09$ & 20 & $1-14-10$ & 16 \\
\hline $2-8-09$ & 18 & $1-15-10$ & 20 \\
\hline $2-9-09$ & 20 & $1-16-10$ & 14 \\
\hline $2-10-09$ & 21 & $1-17-10$ & 21 \\
\hline $2-11-09$ & 28 & $1-18-10$ & 18 \\
\hline $2-13-09$ & 16 & $1-19-10$ & 18 \\
\hline $3-14-09$ & 23 & $1-20-10$ & 16 \\
\hline $2-15-09$ & 17 & $1-21-10$ & 14 \\
\hline $2-16-09$ & $2 I$ & $1-22-10$ & 21 \\
\hline $2-17-09$ & 15 & $1-24-10$ & 18 \\
\hline $2-18-09$ & 22 & $2-28-10$ & 18 \\
\hline $2-19-09$ & 25 & $3-1-10$ & 19 \\
\hline $2-20-09$ & 25 & $3-2-10$ & 22 \\
\hline $2-21-09$ & 25 & $3-3-10$ & 22 \\
\hline $12-22-09$ & 21 & $3-4-10$ & 20 \\
\hline $1-3-10$ & 21 & $3-5-10$ & 20 \\
\hline $1-4-10$ & 24 & $3-6-10$ & 19 \\
\hline $1-5-10$ & 20 & $3-7-10$ & 20 \\
\hline $1-6-10$ & 18 & $3-8-10$ & $:$ \\
\hline
\end{tabular}



TEMPERATURE CHART .

\begin{tabular}{|c|c|c|c|}
\hline : Date : & $\begin{array}{c}\text { Average } \\
\text { Temperature. }\end{array}$ & : Date : & $\begin{array}{c}\text { Average } \\
\text { Temperature. }\end{array}$ \\
\hline $3-8-10$ & 15 & $: 3$ & 21 \\
\hline $3-9-10:$ & 24 & $: 3-21-10$ & 23 \\
\hline $3-10-10$ & 22 & $: 3-22-10$ & 25 \\
\hline $3-11-10$ & 19 & $: 3$ & 26 \\
\hline $3-12-10$ & 19 & $: 3-30-10$ & 20 \\
\hline $3-14-10$ & 12 & $3-31-10$ & 18 \\
\hline $3-15-10$ & 10 & $4-10-10$ & 19 \\
\hline $3-16-10$ & 16 & $4-11-10$ & 22 \\
\hline $3-17-10$ & 22 & $: 4-13-10:$ & 11 \\
\hline $3-18-10$ & 2,1 & $: 4-15-10$ & 23 \\
\hline
\end{tabular}




UNIVERSTYY OF ILLINOIS-URBANA

30112079094204

A

2

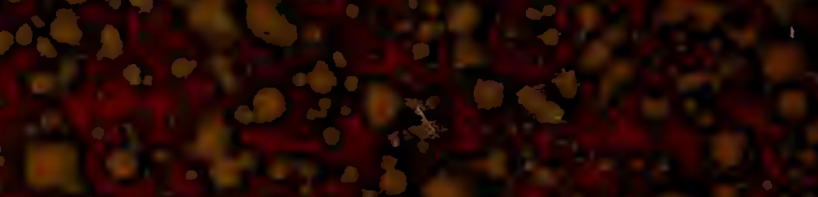

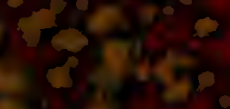

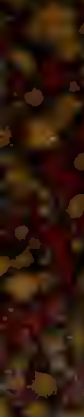

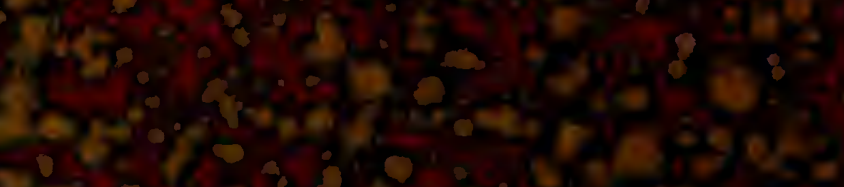

